EASTERN REVIEW 2017, T. 6

\author{
Наталія Петрук
}

\title{
Коммуникация и ее влияние на динамику гражданского общества
}

Органической частью новой социальной и политической реальности, которая объективно формируется в Украине, выступают процессы, свидетельствующие о становлении и функционировании гражданского общества. Основным его структурным элементом становится свободный человек, который утверждает себя в разных формах деятельности и коммуникации, в новых социальных структурах и способах социальной организации. Активность гражданского общества в Украине - это свидетельство того, что страна развивается. Благодаря усилиям людей, которые реализуют свои разнообразные возможности, формируется новая реальность, не вписывающаяся в парадигму однозначных социальных зависимостей и детерминации со стороны государства и его институтов.

Неотъемлемым атрибутом гражданского общества является реформирование экономической, политической, военной структуры, изменения в общественном сознания. От динамичности процессов, которые происходят в разных сферах украинской жизни, зависят перспективы гражданского общества с его неизменными ценностями свободы, уважения к личности, активности общественности, свободного выбора гражданином своей жизни.

Потребность формирования новых форм жизни стимулирует развитие структур гражданского общества. В украинском социуме сложилась весьма сложная ситуация, связанная с усилением влияния на человека государственных, бюрократических структур, официальных институтов. Ухудшает ситуацию также война, которую ведет Украина против агрессора. Это препятствует реализации свободы в системе политической и повседневной жизни, выявлению гражданской активности, реализации инициатив общественности.

Свидетельством динамики процессов в современном украинском обществе является высокий уровень его самоорганизации, функционирование и свободное развитие разноуровневых структур вне рамок государственных и экономических институций. Речь идет о разных гражданских инициати- 
вах, неформальных организациях, волонтерских добровольных объединениях, протестных движениях, свободных человеческих ассоциациях и т.п. Социальная и политическая эффективность их функционирования свидетельствует об очевидном прогрессе в становлении цивилизованных форм человеческой жизни. Естественно, при этом учитывается существенная разница в содержании, ценностях, нормах, которые характеризуют разные типы организованности и разные проявления человеческой солидарности .

Необходимой основой возникновения и успешного функционирования гражданского общества выступает коммуникация. Коммуникация - это универсальная реальность человеческого существования, выражение способности человека к взаимодействию, к возникновению устойчивых связей между людьми в рамках социума. Коммуникация влияет на все без исключения сферы общественной жизни. От характера коммуникации в значительной мере зависят перспективы консолидации той или другой общности вокруг решения важных проблем. Коммуникация обуславливает возникновение новых информационных связей, структур и механизмов влияния на развитие общества, на выбор путей реализации государственной политики.

Уровень развития коммуникации является существенным критерием общественных трансформаций, реализация которых обеспечивается не в последнюю очередь благодаря введению новаций, появлению новых информационных технологий и систем, что в результате выступает необходимым критерием динамичности процессов в обществе, фактором формирования демократических институтов и организаций, системы демократических ценностей. Можно констатировать, что в стратегическом плане жизнь гражданского общества определяется коммуникацией. Особенно заметным это становится в глобальном мире, существование которого возможно благодаря увеличению количества коммуникаций, усилению взаимосвязи между отдельными коммуникациями, расширению отдаленного действия коммуникации на жизнь каждого человека. Это стимулирует пересмотр существующей системы ценностей, их проверку соответственно запросам современного мира.

Коммуникация как стратегический способ развития современного общества открывает новые возможности для человека, позволяет ему освободиться от различных ограничений, дефицитов, систем социального контроля и принуждения, создает условия для пересмотра устойчивых традиционных норм социальной жизни, которые или не отвечают, или отстают от современных тенденций развития. Благодаря коммуникации люди становятся более свободными в реализации повседневных потребностей, в общении и образовании, в использовании свободного времени.

Известный американский социолог А. Этциони отмечает, что коммуникация имеет собственную логику и собственную динамику, что в целом является важным средством в противостоянии, соответствующем вызовам общественного развития. Это способствует открытости общества. Более того, 
стратегическую роль в развитии гражданского общества играет именно открытая коммуникация, которая позволяет распознавать присущие ему проблемы с точки зрения обсуждения разных проблем и противоречий, в том числе и мировоззренческих. Таким образом, посредством коммуникации люди имеют возможность активно влиять на общество и находить адекватные механизмы решения сложных проблем.

Благодаря коммуникации новые знания и доступность новой информации дают человеку возможность расширять границы непознанного, выбирать направление своих действий, отойти от одновекторности и однозначности в принятии решений. Таким образом, человек может максимально реализовать свою свободу. Одновременно это может порождать конфликты и новые противоречия, обострять конкуренцию. Но универсальность коммуникации определяет равные возможности для использования ее преимуществ в жизни.

Качественная специфика современного гражданского общества характеризуется выходом за рамки старых мировоззренчески-ценностных систем. Фактором, который влияет на эти процессы, является, приобретенный в процессе коммуникации, коммуникативный опыт человека, полученные новые знания, информация, знакомство с новым. Неминуемый конфликт ценностей, который может возникать в гражданском обществе, также может быть решен путем налаживания эффективных коммуникаций. Можно утверждать, что новое качественное состояние жизни, новые структуры общественного развития базируются на коммуникации, на новых формах социального взаимодействия.

Коммуникация дает возможность четко запрограммировать общество на определенный тип развития, который гарантирует стабильное функционирование его социальной системы. Организационные и технологические изменения, введение инноваций, утверждение адаптивной идеологии добавляют новые возможности и стимулы для развития гражданского общества.

Динамичность процессов в гражданском обществе определяется использованием механизмов и социальных преимуществ как формальной, так и неформальной коммуникации. Необходимо подчеркнуть, что роль формальной и неформальной коммуникации в функционировании гражданского общества не одинакова. Основанием для разделения формальной и неформальной коммуникации является их отношение к официальным, признанным, документально зафиксированным формам информации. Под формальной коммуникацией понимают набор средств и процессов, правил, процедур и предписаний, которые регулируют движение информации. Она существует для передачи сообщений, которые являются официальными и формируются в соответствии с иерархией власти в организации. Наиболее часто они передаются вертикальными каналами и в письменной форме. Неформальные коммуникации не санкционированы властью. Это такие виды и формы 
общения людей, которые выражают наличие межличностных связей и контактов в той или иной среде.

Формальная коммуникация при всех ее преимуществах означает сужение диапазона выбора и определенное ограничение, даже подчинение объективной воли участника коммуникативных связей предустановленным правилам и процедурам. Она осуществляется без учета личностных особенностей индивидуума, ее требования являются универсальными и стандартными, а ее результаты соотносятся с общепринятыми критериями оценки человеческой деятельности. Таким образом, за своими признаками формальная коммуникация является достаточно однозначной, даже консервативной. А централизованный контроль по ее осуществлению часто препятствует выявлению индивидуальных особенностей человека. По сути, в процессе формальной коммуникации обесцениваются личностные измерения самой коммуникации.

Бесспорно, формальная коммуникация - это нужный и вполне объективный факт человеческой жизни. Однако она не исчерпывает всего богатства коммуникативных связей в обществе. Она не может зафиксировать все способы взаимодействия между людьми и регламентировать все отношения между ними. Кроме формальных способов коммуникации неизбежно должны существовать неформальные. Через неформальное, личностное общение достигается понимание между его участниками, реализуются преимущества человеческой солидарности.

Неформальная коммуникация не сводится к формально предписанным контактам, не является общением «по поводу» выполнения заранее поставленных задач, то есть она не является функционально-ролевой. Неформальная коммуникация не имеет чисто делового характера и не определяется служебными или функциональными требованиями. Она возникает спонтанно и является результатом длительных контактов индивидов как личностей. Неформальная коммуникация развивается как своего рода социальное пространство действия межличностных норм и связей. В отличие от формальной коммуникации, которая характеризуется предметной, функциональной направленностью, неформальная характеризует такие отношения между людьми, которые основываются на взаимности, открытости отношений, преимущественно глубоко личностных, в отличие от анонимных или чисто функциональных. Неформальная коммуникация объединяет небольшой контингент людей, которые сравнительно долго поддерживают между собой личностные, непосредственные связи. Их объединяет взаимная заинтересованность друг в друге, дружба, взаимные симпатии, общие интересы и ценности. Неформальные связи значительно сильнее, нежели формальные, стимулируют распространение проявлений дружбы, сотрудничества и взаимопомощи.

Естественно, сложно говорить о четко определенных параметрах и преимуществах неформальной коммуникации. Но очевидным есть то, что она 
направляется на конкретного человека, на личность. Именно благодаря своей личностной ориентации неформальная коммуникация выступает своеобразным антитезисом нечеткости и анонимности коммуникации формальной. Важными чертами неформальной коммуникации выступают спонтанность, то есть внеплановость ее возникновения, возможность сосуществования параллельно с формальной коммуникацией, добровольность устанавливаемых связей между людьми, свобода выбора личностных контактов. Следует отметить ее чрезвычайную «своевременность», лабильность по отношению к изменениям, которые происходят в обществе. Неформальные связи и неформальная коммуникация возникают тогда, когда в этом ощущается особенная потребность именно в них, а не формально предписанных связях.

В неформальной коммуникации могут проявляться альтернативные подходы к обсуждению и разрешению разных проблем, что в свою очередь стимулирует человеческую деятельность. Существование какой-либо альтернативы в социуме - это потенциальная возможность формирования автономных структур гражданского общества. Одним из больших преимуществ неформальной коммуникации является то, что межличностному общению присуща активная природа. В неформальной коммуникации редко используются односторонние связи, однонаправленное общение. Ей свойственна преимущественно обратная связь (двусторонний или многосторонний обмен мыслями). Кроме того, на основе взаимной заинтересованности участников неформальной коммуникации развивается еще одно ее свойство - избирательность (адресность) неформальных связей и контактов. Они возникают только тогда и только между теми людьми, которые заинтересованы в общении.

Неформальная коммуникация ориентирована на конкретного «потребителя»: решение о том, когда или кому что-то сообщить, почти полностью зависит от конкретного человека, который является носителем информации. Эта ориентация на потребителя, во-первых, поднимает доступность и понятность того, о чем сообщается в акте коммуникации. А во-вторых, с помощью межличностной коммуникации удовлетворяется неосознанная и зачастую неартикулированная информационная потребность: такая коммуникация дает потребителю информацию, которая выявляется для него полезной, хотя сам он ее и не искал. И в-третьих, межличностные каналы несут, как правило, такую информацию, которая дополняет функционирование формальных каналов передачи информации. При этом межличностные каналы требуют сравнительно небольших затрат сил и времени от конкретного человека. Для осознания преимуществ, свойственных неформальной коммуникации, значение имеет также и то, что благодаря межличностным контактам и межличностному общению передается так называемое "неформулируемое содержание", которое не обязательно должно выражаться в четких понятиях и категориях и которое воспринимается именно благодаря наличию в обществе неформальных контактов и связей, общих целей и интересов . 
Осознавая значение и ценность неформальной коммуникации, очень сложно количественно измерить эффективность и преимущества неформальных способов общения и межличностных связей. В то же время несоответствие формальной коммуникации запросам общества может быть своеобразным показателем того, насколько формальная коммуникация является «адекватной» объективным требованиям дня. Поэтому неформальная коммуникация играет очень важную роль в гражданском обществе, выполняя целый ряд социальных функций. Несмотря на то, что постоянный прогресс и нововведения в коммуникационной сфере позволяют формальным механизмам оставаться существенным фактором в человеческой жизни, неформальная коммуникация не теряет своего значения в трансляции информации в обществе. Кроме того, эффективность использования формальной или неформальной коммуникации зависит во многом от социальных или культурных особенностей человеческих общностей. С целью повышения оптимизации их деятельности в гражданском обществе должны осуществляться попытки формализации и планирования коммуникации. Однако если формальных контактов и формальных связей выявляется недостаточно для нормального функционирования социальных структур, их дополняет или заменяет именно неформальная коммуникация.

Можно констатировать, что формальная и неформальная коммуникации, выполняя присущие им социальные функции, взаимодополняют друг друга в гражданском обществе. Но при определенных условиях существует угроза доминирования формальной, официальной коммуникации, вхождения ее в рамки повседневной жизни человека, влияния ее на создание и распространение форм экономической или бюрократической рациональности в обществе тогда, когда структуры гражданского общества являются слабыми, а неформальная коммуникация почти отсутствует. В таких условиях человек выступает не как личность, а как функционер. Несмотря на то, что через формальную коммуникацию увеличивается возможность координации разных видов человеческой деятельности, строгий контроль по решениям и действиям людей часто является неэффективным и может привести к возникновению социального напряжения.

Следствием тотального господства формальной, официальной коммуникации в обществе может быть администрирование и бюрократизация жизни, нивелирование значения тех жизненных форм, которые воплощают ценности взаимопонимания, вытеснение моральных регулятивов рациональной целесообразностью. К тому же возможности и преимущества формальной коммуникации активно использует власть.

Демократичность и цивилизованность обсуждения и решения сложных жизненных и политических проблем в гражданском обществе достигается, как правило, путем рационального сочетания преимуществ формальной и неформальной коммуникации. Тотальная формальная коммуникация не может 
быть абсолютно верным образом тех реальных процессов, которые происходят в украинском обществе. Поэтому вполне закономерным является то, что в украинском обществе, особенно в кризисные, экстремальные периоды его развития происходит укрепление автономного пространства межличностного общения, распространение разных форм дискурса общественности.

Процесс формирования гражданского общества в Украине хотя и медленно, но осуществляется. Динамика развития гражданского общества зависит от соотношения разных социальных сил, от наличия условий, необходимых для наиболее полной реализации потенциала каждого человека и, конечно, от использования потенциала коммуникации. Именно через коммуникацию, дискурс и диалог осуществляется рациональное урегулирование конфликтов, достижение регулированного соглашения.

Одним из самых главных условий развития и укрепления гражданского общества в Украине является коммуникация власти и общественности. Это касается, прежде всего, процессов институционализации коммуникации власти и государства, институционального обеспечения коммуникативной деятельности в органах законодательной и судебной власти, в местных и центральных органах власти, в разработке механизмов координации органов власти с общественностью. В Законе Украины "Об основах государственной коммуникативной политики" следует учесть рекомендации о внедрении системы связей с общественностью. Низкий уровень координации общественных организаций, слабая коммуникация с ними, отсутствие публичности в сфере политики является причиной неэффективности государственного управления и, что самое главное, свидетельством отрыва власти от граждан.

Фактически все задания, связанные с коммуникацией власти и общественности, должны решаться через деятельность коммуникативных подразделений государственной власти. Ключевыми шагами, которые уже были осуществлены на пути институционализации коммуникативных отношений власти и общественности в Украине могут быть:

- обязательность образования структурных подразделений по вопросам взаимодействия с СМИ и связей с общественностью в аппаратах центральных и местных органов исполнительной власти;

- гарантирование права на информацию через образования в государственных органах власти специальных информационных служб или систем, которые обеспечивали бы в установленном порядке доступ к информации;

- реализация государственной политики по вопросам прозрачности и открытости органов исполнительной власти;

- одобрение Концепции проекта Закона Об основах государственной коммуникативной политики.

Следует отметить, что сегодня вопросы коммуникативного взаимодействия органов государственной власти, органов местного самоуправления, СМИ, общественности разбросаны в ряде нормативно-правовых актов, ча- 
стью которых есть решения Кабинета Министров Украины. Поэтому важные инструменты коммуникации власти и общественности (речь идет о консультациях с общественностью, гражданскую экспертизу и т.п.) распространяются только на исполнительную ветвь власти. Отсутствуют общие стандарты информационного обмена между властью и общественностью. До сих пор остаются неопределенными механизмы осуществления гражданского контроля за деятельностью органов власти. В органах законодательной и судебной власти Украины нет подразделений по связям с общественностью, а коммуникативное обеспечение ограничивается функционированием пресс-служб. Вместе с тем в местных ОГА четко определены подразделения, которые отвечают за коммуникацию. Прежде всего, это управления (отделы, сектора) по вопросам внутренней политики и связям с общественностью. Есть также подразделения по делам прессы и информации. Функциональные обязанности и сферы влияния этих структурных единиц четко разграничены. Однако на уровне центральных органов государственной власти четкой организации во взаимодействии власти и общественности не прослеживается.

Естественно, власть использует в большей мере потенциал и эффективность формальной коммуникации. Разработаны и функционируют четко определенные механизмы координации органов власти по связям с общественностью. Это - координация работы пресс-служб и соответствующих информационно-аналитических подразделений органов исполнительной власти через пресс-службу Президента Украины, координация при подготовке материалов, которые передаются средствам массовой информации и содержат оценки внешней и внутренней политики государства, координация работы по образованию в составе аппаратов центральных и местных органов исполнительной власти управлений или отделов по вопросам взаимодействия со средствами массовой информации и связям с общественностью и т.п. Однако ситуация в этой сфере до сих пор не совсем скоординирована и оптимальна. Поэтому эксперты и аналитики предлагают институционализировать координирующий центр реализации государственной коммуникативной политики. Считается, что эти полномочия целесообразно передать Госкомтелерадио, который должен предоставлять методическую помощь пресс-службам, другим соответствующим подразделениям по вопросам взаимодействия органов исполнительной власти со средствами массовой информации и общественностью.

Таким образом, государством должна проводиться целостная коммуникативная политика. С одной стороны, только лишь институциональное упорядочение и должная координация в сфере коммуникации сделают возможным адекватную и непротиворечивую репрезентацию действий власти населению, обеспечит налаживание системной обратной связи. С другой стороны, сила и действенность гражданского общества в Украине может ре- 
ализовываться через активность граждан, представления ими своей позиции и интересов путем создания автономных и эффективных механизмов неформальной коммуникации.

Естественно, большинство преимуществ, которые присущи неформальной коммуникации, формальные, официальные системы или уже имеют, или могут иметь, или хотя бы допускают существования схем, способных выполнять при благоприятных условиях соответствующие функции. Формальные, официальные механизмы коммуникации часто являются более эффективными. Однако возможности и преимущества неформальной коммуникации становятся очевидными в тех ситуациях, которые требуют личных контактов, быстрого обмена информацией. Но в любом случае в единстве своих схем, механизмов и связей формальная и неформальная коммуникация являются не только источником информации. Она есть реальностью гражданского общества, необходимым условием его функционирования и динамического развития, предпосылкой изменений во всех сферах общественной жизни.

\section{Библиография}

Тематический отчет. Гражданское общество и кризис в Украине, ОБСЕ, 11.02.2015, http://www.osce.org/ru/ukraine-smm/217526?download=true (17.11.2015).

Гладких В., Блеск и нищета гражданского общества в Украине, 16.12.2015, https:// daily.rbc.ua/rus/show/blesk-nishcheta-grazhdanskogo-obshchestva-1450269774. html (17.11.2015).

Гражданское образование и демократизаџия в странах Восточного партнерства, Д. Зегерт (ред.-сост.), „Bundeszentrale für politische Bildung”, т. 1698,14.03.2015, http://www.bpb.de/shop/buecher/schriftenreihe/222930/- (17.11.2015).

Karatzogianni A., Miazhevich G., Denisova A., A Comparative Cyberconflict Analysis of Digital Activism Across Post-Soviet Countries, "Comparative Sociology" 2017, vol. 16 , no. 1 .

Про засади державної мовної політики, “Відомості Верховної Ради (ВВР)” 2013, № 23, ст. 218, http://zakon2.rada.gov.ua/laws/show/5029-17/print1331482006276224 (17.11.2015).

Середакандидат Ю., Украинский парадокс: сильное гражданское общество, которое слабо влияет на власть, https://delo.ua/ukraine/ukrainskij-paradoks-silnoegrazhdanskoe-obschestvo-kotoroe-slabo-314682/ (17.11.2015).

Udovyk O., Beyond the Conflict and Weak Civil Society; Stories from Ukraine: Cases of Grassroots Initiatives for Sustainable Development, "East/West: Journal of Ukranian Studies" 2017, vol. 4, no. 2. 
Natalia Petruk

\section{Komunikacja i jej wpływ na dynamikę rozwoju społeczeństwa obywatelskiego}

Artykuł poświęcony jest analizie treści, specyfice i roli komunikacji w procesie rozwoju społeczeństwa obywatelskiego na Ukrainie. Komunikacja postrzegana jest jako rzeczywistość cywilizowanego funkcjonowania ukraińskiego społeczeństwa. W artykule rozważane są również zalety odwoływania się do form formalnej i nieformalnej komunikacji.

Słowa kluczowe: społeczeństwo obywatelskie, komunikacja, formalna i nieformalna komunikacja, rozwój społeczeństwa obywatelskiego, Ukraina.

\section{Natalia Petruk}

\section{Communication and its impact on the dynamics of civil society}

The article analyzes the content, features and the role of communication in the development of civil society in Ukraine. Communication is considered as the reality of civilized existence of the Ukrainian community. The emphasis is on the importance of the benefits of formal and informal communication.

Keywords: civil society, communication, formal and informal communication, development of civil society, Ukraine. 